\title{
Let the Users Tell the Truth: Self-disclosure Intention and Self-disclosure Honesty in Mobile Social Networking \\ Le Wang ${ }^{12}$, Jie Yan ${ }^{3}$, Jun Lin ${ }^{1}$, Wentian Cui ${ }^{1}$ \\ ${ }^{1}$ School of Management, Xi' an Jiaotong University, Xi' an, China 710049 \\ ${ }^{2}$ Sociology, University of Chicago, Chicago, U.S.A. 60637 \\ ${ }^{3}$ Grenoble Ecole de Management, Grenoble, France 38003
}

\begin{abstract}
Large amounts of customer data present rich business opportunities. Drawing on the privacy calculus model, this study investigates the antecedents of self-disclosure intention and self-disclosure honesty. We extend the privacy calculus model by exploring how the characteristics of service providers and the interpersonal difference of users influence privacy trade-off. An online empirical survey that involves 913 respondents was conducted. We find that both monetary rewards and social rewards positively predict self-disclosure intention, whereas only social rewards positively predict self-disclosure honesty. Moreover, application reputation and flow experience of users weaken the perceptions of privacy concern, and application compatibility and flow experience strengthen the perceptions of social rewards. Our results suggest that users place more weight on social rewards than on monetary rewards. Therefore, service providers are advised to create salient and distinct social rewards. They can also adopt distinct marketing strategies based on their profiles and the interpersonal difference of their users.
\end{abstract}

Keywords: self-disclosure intention; self-disclosure honesty; mobile social networking; social rewards; privacy concern; flow experience; self-esteem

Le Wang obtained his Ph.D from the School of Management, Xi'an Jiaotong University, China. His researches focus on the privacy calculus model, human behaviours in the age of information, and the economics of privacy. Currently, he is a visiting scholar at the Sociology, University of Chicago. His works have been accepted by Technology Analysis \& Strategic Management and J. of Business Strategy. Le Wang is the corresponding author and can be contacted at lewang@uchicago.edu

Jie Yan is an associate professor of Grenoble Ecole de Management, France. He holds a Ph.D in Management Science and Systems from Hull University, UK. His researches focus on innovation adoption and information management. His works have appeared on $R \& D$ Management, Int. J. Technology Management, Technology Analysis \& Strategic Management, J. of Business Strategy, and Int. J. of Information Management.

Jun Lin is a professor of Management Science and Engineering at Xi'an Jiaotong University, China. He holds a Ph.D in Industrial Engineering from National University of Singapore, Singapore. His research interests pertain to new product development and technology management. He has published over 30 articles in refereed journals, including IEEE Trans. on Engineering Management, Eur. J. of Operational Research, Int. J. of Production Research, Eur. Management J. and 
Complexity. Dr. Jun Lin was recognized as one of the China's Highly-cited researchers by Elsevier.

Wentian Cui is a professor at Xi' an Jiaotong University, China. He holds a Ph.D in Management Engineering from University of Tsukuba, Japan. His researches focus on complex networks. His works have appeared on Eur. J. of Operational Research, Int. J. of Production Research and Complexity.

Acknowledgements: We would like to thank the regional editor and three anonymous reviewers for their constructive comments. Errors and omissions remain ours. We are deeply grateful for the feedbacks from Alessandro Acquisti and Liad Wagman. This research was funded by China Scholarship Council and Chinese National Science Foundation (Grant Nos.71472146 and 71072128). 


\section{Introduction}

The popularity of mobile devices has made mobile social networking an indispensable part of people's daily lives (Fan \& Gordon, 2014). Statistics show that the mobile daily active users of Facebook reached 989 million in March 2016 (Facebook, 2016). Approximately half of the mobile Twitter users log on to their account the moment they wake up (Twitter, 2015). Activities on social media leave trails of data that expose users' interests, beliefs, and intentions. By utilizing social media analytics techniques, such as opinion mining, sentiment analysis, and social networks, large amounts of customer data have become gold mines for exploiting potential business opportunities (Erevelles, Fukawa, \& Swayne, 2016; Gandomi \& Haider, 2015).

However, the misuse of personal information is alarming (Awad \& Krishnan, 2006). Individuals under the risks of privacy invasion tend to avoid self-disclosure, disclose incomplete information, or manipulate their profiles (Acquisti, Brandimarte, \& Loewenstein, 2015). Failure to encourage self-disclosure or obtain inaccurate customer information may cause social and economic impacts (Mason \& Harris, 2005; Robertshaw \& Marr, 2006). Therefore, it is highly important to understand the factors that predict users' self-disclosure intention and self-disclosure honesty.

The privacy calculus model, which argues that self-disclosure intentions are determined by the rational calculus of the benefits and costs of privacy behaviours, is widely adopted in information system (IS) literatures (Dinev \& Hart, 2006; Jiang, Heng, \& Choi, 2013; Wang, Duong, \& Chen, 2016). Külcü and Henkoğlu (2014) revealed that the concern for the loss of privacy is a significant barrier for self-disclosure in the information age. Monetary rewards, such as cash bonus, discounts and coupons can compensate the privacy concerns of disclosing personal information in online transactions (Posey, Lowry, Roberts, \& Ellis, 2010). Social rewards, such as pleasure, satisfaction, and relationship development may also offset the risks of privacy invasions (Jiang et al., 2013; Z. Liu, Min, Zhai, \& Smyth, 2016). Individuals perform a costs-benefits calculus before self-disclosure and they may disclose their personal information if the benefits outweigh the costs. Recent studies have enriched the concepts of costs and benefits in the privacy calculus model. For instance, the concept of costs has been extended to multiple aspects such as trust in service providers (Chang, Cheung, \& Tang, 2013) and sensitivity toward personal information (Bansal \& Gefen, 2010). The concept of benefits has been extended to perceived usefulness (Hess, McNab, \& Basoglu, 2014), relationship building and maintenance (Ellison, Vitak, Gray, \& Lampe, 2014), and emotional support (Oh, Ozkaya, \& LaRose, 2014). Several gaps have emerged from the existing literatures.

First, the antecedents of self-disclosure intention have been recognized (Posey et al., 2010; Wang et al., 2016; Zhao, Lu, \& Gupta, 2012), whereas those of self-disclosure honesty have been given less attention. Misrepresentations and deceptions commonly occur in virtual social interactions (Krasnova, Spiekermann, Koroleva, \& Hildebrand, 2010). Moreover, inaccurate information causes substantial social and economic impacts. For example, inaccurate customer data may mislead manager's strategic decisions (Mason \& Harris, 2005) and create bias in the research 
of marketing scholars (Robertshaw \& Marr, 2006). Thus, the first objective of this study is to investigate the factors that predict sincere and accurate self-disclosure.

Second, previous studies fail to differentiate the roles played by social rewards and monetary rewards in predicting privacy protective behaviours. Existing studies on the privacy calculus model focus on either monetary (Premazzi et al., 2010) or social rewards (Jiang et al., 2013) in offsetting privacy risks. Other studies that propose social and monetary rewards jointly predict privacy protective behaviours have integrated them into an aggregate construct (Youn, 2009). Social and monetary rewards differ in predicting behaviours (Deci, Koestner, \& Ryan, 1999). For example, individuals in search for emotional supports are willing to disclose their inner feelings. Conversely, individuals may share a superficial self-disclosure for monetary rewards. Therefore, the second objective of this study is to provide a comprehensive understanding of the privacy calculus model by differentiating the roles of social and monetary rewards.

Third, the privacy calculus model views the privacy protective behaviours as a result of a rational calculus of the costs and benefits. However, not all individuals are rational, and an individual cannot be rational at all times. The perceptions of privacy concerns and rewards, especially social rewards, are influenced by interpersonal difference and contextual settings (Acquisti et al., 2015). For example, adults have a higher reward threshold for self-disclosure than teenagers (Youn, 2009). Individuals who are addicted to a certain type of activity may ignore or downplay the negative effects of that activity (Partington, Partington, \& Olivier, 2009). Contextual settings influence the way people manage their privacy. For instance, we may reveal personal information to a stranger on a plane, which rarely happens in other situations. Legal regulations are positively related to the intention of disclosing personal information (Andrade, Kaltcheva, \& Weitz, 2002). In general, the privacy protective behaviours vary with interpersonal differences and specific contexts given certain amounts of rewards and risks. Thus, the third objective of this study is to explore the influence of interpersonal difference and contextual settings on privacy trade-off.

The results of the present study inform theory and practice in several aspects. Investigating the antecedents of self-disclosure honesty provides a comprehensive understanding of privacy protective behaviours. We differentiated the roles of social rewards and monetary rewards in predicting privacy protective behaviours. Moreover, we provided evidence that privacy trade-off depends on interpersonal difference and contextual settings. This study offers practical insights as well. For self-disclosure intention, we found that users of mobile social media place more weight on social rewards than on monetary rewards. Monetary rewards were not found to predict self-disclosure honesty. These findings suggest that service providers should exert additional effort to create salient and distinct social rewards. Operators of social media are suggested to broaden their brand awareness, as we found that application reputation helps attenuate the perceptions of privacy concern. The flow experience of users has been shown to mitigate the perceptions of privacy concern and strengthen the perceptions of social rewards. Service providers are encouraged to maximize the 
flow experience of their users. Given that high self-esteem increases the perceptions of privacy concern, administering a self-esteem test before registering is advised such that service providers can recommend optional privacy policies. Overall, the results indicated that service providers may adopt distinct marketing strategies based on their profiles and the interpersonal differences of their users.

\section{Theoretical Background and Hypotheses Development}

\subsection{Self-disclosure and Privacy Calculus}

Self-disclosure refers to the act of revealing personal information, such as locations, hobbies, and photos when registering or using mobile social networks (Posey et al., 2010). The user-generated data can possibly benefit academic scholars and business managers. The popularity of mobile social networking enables operators to collect large amounts of customer data. The "big data" of customers provide an ideal source for academic scholars in investigating consumer behaviours (Robertshaw \& Marr, 2006). By utilizing social media analytics techniques, customer data are rich in opportunities for improving customer satisfaction and service quality (Fan \& Gordon, 2014; Wang et al., 2016). However, individuals increasingly suffer from information misuse (Awad \& Krishnan, 2006). Avoiding self-disclosure and deceptions are commonly adopted strategies for protecting privacy (Acquisti et al., 2015). For instance, users may manipulate their profiles for the purpose of conveying positive images to others (Krasnova et al., 2010). Users facing privacy risks may create and convey false information to others through synchronous online interactions (Jiang et al., 2013). Thus, the factors that drive sincere self-disclosures deserve further investigation.

Any social behaviour may result in costs and benefits. The privacy calculus model argues that individuals perform a costs-benefits analysis before self-disclosure (Dinev \& Hart, 2006). In the context of mobile social interactions, one of the major threats of self-disclosure is the concerns for privacy invasion (Külcü \& Henkoğlu, 2014). Users who disclose personal information may obtain social rewards, such as developing and maintaining intimate relationships with peers or monetary rewards, such as coupons, cash bonuses, and discounts. Essentially, individuals conduct a privacy calculus in which privacy concerns are weighed against perceived benefits when deciding whether to disclose personal information.

Privacy protective behaviours vary with interpersonal differences and specific contexts. Individuals who are highly sensitive toward personal information have greater concerns for privacy invasion and are thus less likely to self-disclose (Korzaan \& Boswell, 2008). Similarly, persons with high self-esteem are highly self-protective (Crocker, Thompson, McGraw, \& Ingerman, 1987). Individuals can exhibit any sentiment ranging from extreme concern to apathy about privacy depending on the situation. For example, the Chinese are open about financial matters, such as income, housing cost, and possession, which are private matters for most Western populations (Acquisti et al., 2015). The privacy calculus model provides a general foundation for predicting self-disclosure and taking interpersonal difference and contextual settings 
into account provides a comprehensive framework.

\subsection{Characteristics of Service Providers and Privacy Trade-off}

The contextual settings and interpersonal difference influence privacy protective behaviours. Knowledge on the specific mechanisms through which contextual settings and interpersonal difference affect privacy protective behaviours is limited. The privacy calculus model posits that individuals perform a costs-benefits analysis to determine privacy protective behaviours, how users' contextual settings and interpersonal difference influence the perceptions of privacy concerns and perceived rewards require further investigation. Contextual factors, such as legal environment, cultural differences, and characteristics of service providers, have been shown to be associated with privacy trade-off (Acquisti et al., 2015). Previous studies have revealed that legal regulations and users' perceptions of the privacy policy released by service providers mitigate concerns over privacy invasion (Andrade et al., 2002). Other studies have noted that individuals' privacy protective behaviours vary with service providers (Eastlick, Lotz, \& Warrington, 2006; Lin, 2011). Eastlick et al. (2006) found that high firm reputation in business-to-customer transactions leads to less privacy concern. Lin (2011) argued that the compatibility of mobile applications positively affects privacy disclosure because compatible applications fit the values and needs of users. In this section, we therefore examine the effects of the characteristics of mobile social applications on privacy concerns and perceived rewards by controlling for legal environments and perceptions of privacy policy. In this paper, perceived rewards are defined as the social and monetary rewards obtained from using mobile social media.

2.2.1 Application Compatibility. Perceived compatibility is the degree to which a mobile application is perceived to be consistent with users' existing values, previous experiences, and needs (Gillenson \& Sherrell, 2002). Compatibility can increase the adoption of a mobile application and reduce the potential uncertainty of using that application (Ozturk, Bilgihan, Nusair, \& Okumus, 2016). The perceived compatibility of an application is associated with the extent to which the application aligns with users' social and cultural environments. Mobile applications that are highly compatible can better satisfy existing values and psychological needs of its users (Fershtman \& Weiss, 1998), which are critical components of social rewards. In summary, these studies suggest that perceived compatibility positively predicts social rewards. Hence, we posit the following:

\section{H1 Application compatibility is positively associated with social rewards.}

2.2.1 Application Reputation. Application reputation refers to users' collective judgments of an application based on assessments of its social and economic effects over time. Reputation describes whether a mobile social application is widely adopted and recognized by users. Application reputation contributes to building and maintaining social relationships, which are important components of social rewards (Z. Liu et al., 2016). Relationship building refers to users' ability to build new connections with unknown users via mobile social applications, and relationship 
maintaining refers to users' ability to maintain an intimate relationship with existing friends. High reputation indicates that a mobile application is widely accepted and has a large number of active users. Having a large number of active users increase the probability of making new friends. As applications become popular, they are more likely to cover the existing friends of their users. The popularity of highly reputed applications enables their users to maintain and closely interact with their existing friends. Hence, we hypothesize the following:

\section{H2 Application reputation is positively associated with social rewards.}

IS studies have long recognized that trust contributes to ease users' privacy concern (C. Liu, Marchewka, Lu, \& Yu, 2005; Xu, Teo, Tan, \& Agarwal, 2012). Considering that trust plays a central role in building long-term relationships with customers (Doney \& Cannon, 1997), service providers are unlikely to have loyal users in the absence of trust. Once the customers have confidence in service provider's privacy policy and privacy protection practices, they will have fewer concerns over privacy invasion. However, many people develop privacy concerns in online transactions mainly because of a lack of trust in online shops (Hoffman, Novak, \& Peralta, 1999). King-Casas et al. (2005) found that in the context of social exchange, brand reputation is strongly related to trust. Gefen et al. (2003) suggested that consumers recognize the differences in reputation among online stores, and those differences influenced their assessments of store trustworthiness and perceptions of privacy invasions (Gefen, Karahanna, \& Straub, 2003). Therefore, we argue that the reputation of mobile social applications positively affects consumer's perception of trustworthiness, thereby decreasing the privacy concern of users. Thus, we hypothesize the following:

H3 Application reputation is negatively associated with privacy concern.

\subsection{Interpersonal Difference and Privacy Trade-off}

The perceptions of costs and benefits of self-disclosure in social interactions vary with interpersonal difference. People are often unaware of the consequences of disclosing personal information, thereby influencing their judgments of the costs. Individuals may hold a conservative attitude toward self-disclosure if they have ever experienced privacy invasions. Crocker et al. (1987) argued that persons with high self-esteem are highly self-protective. Self-protective perception is negatively related to self-disclosure intention. People who are completely immersed in a certain type of activity may ignore the concerns of privacy invasions unconsciously. In this section, with privacy invasion experience controlled for, we examine the influence of interpersonal difference (self-esteem and flow experience) on privacy concern and perceived rewards.

2.3.1 Self-esteem. Self-esteem refers to the self-evaluation that individuals make with regard to themselves (Pierce \& Gardner, 2004). In this paper, privacy is defined as the claim of individuals to determine when, how, and to what extent their personal information is transmitted to others (Campbell, 1997). Privacy concern refers to the 
subjective views of fairness within the context of privacy. Scholars argue that self-esteem is associated with individuals' reaction to potential threats and that persons with high self-esteem are very self-protective (Crocker et al., 1987). Moreover, a high sense of self-esteem leads to increased sensitivity to privacy (Bearden, Hardesty, \& Rose, 2001). For a given probability of privacy invasions, individuals with high self-esteem are more concerned than individuals with low self-esteem. Hence, we posit the following:

\section{H4 Self-esteem is positively associated with privacy concern.}

2.3.2 Flow. In this paper, flow is defined as an extremely enjoyable experience, in which an individual engages in mobile social networking with total involvement, enjoyment, control, and concentration (Hsu \& Lu, 2004). Flow is characterized by a state of total involvement that time and place have been forgotten. Flow experience result in a win-win situation for both users and service providers. For example, flow experience on the web is positively related to the satisfaction with websites (Deng, Turner, Gehling, \& Prince, 2010), websites' usefulness, perceived ease of use (Agarwal \& Karahanna, 2000), and the intention to use websites (Sanchez-Franco, 2006). With the growing popularity of mobile social networking, an increasing number of teenagers are experiencing flow in mobile social media. Specifically, nearly half of the mobile Twitter users $\log$ on to their account the moment they wake up (Twitter, 2015). Moreover, users refresh and check their Facebook pages every few minutes to maintain updated communication with peers (Błachnio, Przepiorka, \& Pantic, 2016).

Social rewards refer to the pleasure, satisfaction, and enjoyment that users obtained from using mobile social networking (Jiang et al., 2013). People attach significant importance to social rewards obtained from the activities in which they experience flow. For example, teenagers spend a large amount of time to obtain the virtual titles in games they are immersed in (Mäntymäki \& Salo, 2015). As we defined above, the flow experience is related to pleasant and enjoyable activities (Hsu \& Lu, 2004). Study argues that flow experience acts as the 'glue' that holds the consumer in the hypermedia computer-mediated environment (Hoffman \& Novak, 1996). Studies have found that flow experience is positively related to perceived usefulness of websites (Agarwal \& Karahanna, 2000) and satisfaction with websites (Deng et al., 2010). Pleasure, satisfaction, and enjoyment are critical components of social rewards. Therefore, we hypothesize the following;

H5 Flow experience is positively associated with social rewards.

Flow experience is characterized by a loss of self-consciousness and a feeling of control (Csikszentmihalyi, 1990). Individuals who are high in flow may become much absorbed that they manifest the tendency of addiction (Koufaris, 2002). Individuals addicted to a certain type of activity are apt to unconsciously ignore the negative effects of that activity (Partington et al., 2009). On the other hand, Csikszentmihalyi (1990) noted that "the flow experience itself is so enjoyable that people will do it even at great cost, for the sheer sake of doing it" (p.4). Flow experience may hinder the 
potential threats. Individuals experiencing flow are highly motivated to carry out further (or even risky) activities to experience flow again (Engeser \& Rheinberg, 2008). Therefore, users may ignore or downplay privacy concerns if they experience flow in using mobile social media. Taken together, we assume the following:

H6 Flow experience is negatively associated with privacy concern.

\subsection{Privacy Trade-off and Privacy-protective Behaviours}

2.4.1 Perceived Rewards. As discussed above, perceived rewards refer to the social and monetary rewards obtained from using mobile social media. Monetary rewards refer to tangible benefits such as coupons, discounts, and promotion deals. The privacy calculus model asserts that individuals weigh the costs and benefits of social behaviour. Although privacy concerns may diminish the desire for self-disclosure, individuals disclose their personal information occasionally because of the provided monetary rewards. A study found that users are willing to reveal their private information, such as household income and stocks portfolio, when they were compensated with sufficient monetary rewards (Hann, Hui, Lee, \& Png, 2007). Similar results have been found among teenagers who are willing to self-disclose for cash rewards (Youn, 2009). Game companies, such as Pokerstars and World of Warcraft, encourage users to disclose their personal information by offering game currency and privilege cards. In summary, monetary rewards reduce the concern over privacy invasion. Thus, we posit the following:

H7 Monetary rewards are positively associated with self-disclosure intention.

Monetary rewards and self-disclosure honesty are positively related for two reasons. First, individual is a rational human being who is interested in maximizing his or her own payoffs. Psychological studies have argued that there is nothing special about the decision to be honest, which depends on the expected benefits and costs of being honest (Mazar \& Ariely, 2006). Perceived external benefits, such as more money and a better position, are positively related to honesty (Mazar \& Ariely, 2006). Second, individuals have the desire to act ethically (Ford \& Richardson, 1994). Truthful information from the customers is critical for service providers. It is unethically for the users to obtain monetary rewards from service providers while fabricate their personal information. Therefore, we formulate the following hypothesis:

H8 Monetary rewards are positively associated with self-disclosure honesty.

Social rewards refer to the satisfaction, pleasures, and enjoyment obtained by using social media. Individuals who gain pleasure and enjoyment through interacting with friends will undertake significant efforts to develop and maintain those relationships (Tidwell \& Walther, 2002). Self-disclosure contributes to maintaining and developing social relationships. For instance, common interests are critical for making new friends (Bargh, McKenna, \& Fitzsimons, 2002). Social media users who 
disclose their hobbies are likely to find other users with common interests. Individuals in reciprocal social interactions are bound by a fair exchange of information (Lawler \& Thye, 1999). Social media users who provide their personal information to others desire the similar amount and depth of information from others (Ellison et al., 2014). Therefore, users are likely to self-disclose if compensated with substantial amount of social rewards. Thus, we formulate the following:

\section{H9 Social rewards are positively associated with self-disclosure intention.}

Social rewards and self-disclosure honesty are positively related. Social rewards are derived from intimate relationships with friends. In particular, honest and sincere self-disclosure forms the basic tenet of maintaining an intimate relationship (Ben-Ze'ev, 2003). A long-term relationship requires truthfulness. When making friends, individuals favour those who disclose considerable information about their inner core or true self. Manipulating personal information and providing inaccurate impressions are perceived to violate the mutual agreement of openness and authenticity with others (Argo, White, \& Dahl, 2006), the discovery of which may cause disastrous consequences for existing relationships. In general, individuals are less willing to risk violating the exchange norms in an intimate relationship and are thus likely to disclose truthful information. Thus, we posit the following:

H10 Social rewards are positively associated with self-disclosure honesty.

2.4.2 Privacy Concerns. Disclosing personal information may have accrual benefits for users, such as maintaining intimate relationships with peers and obtaining emotional support. However, this behaviour entails potential risks. Given that self-disclosure often involves highly intimate information and inner feelings in some cases, users may become vulnerable. Users with high privacy concern lack confidence in relying on others (Jiang et al., 2013). These users are anxious that their privacy may be at risk of being exploited and misused (Debatin, Lovejoy, Horn, \& Hughes, 2009). When facing privacy threats, the commonly adopted strategy is to refuse the requirement for personal information (Dinev \& Hart, 2006).

Individuals under the threat of privacy invasion tend to disclose incomplete or inaccurate information to protect their privacy as well as maintain the flow of interactions (Jiang et al., 2013). For example, girls may be requested for contact information by online friends when using mobile social applications. They may fabricate such information to reduce their vulnerability to others' opportunistic behaviour. Supplying personal information that is designated as a compulsory field to complete registration is mandatory. Therefore, users may manipulate their personal information if they develop concern regarding information misuse (Krasnova et al., 2010). Taken together, we assume the following:

H11 Privacy concern is negatively associated with self-disclosure intention.

H12 Privacy concern is negatively associated with self-disclosure honesty. 


\section{Methodology}

\subsection{Research Setting and Questionnaire Design}

Users are required to disclose their phone numbers and e-mail address to complete their registrations. Users of mobile social applications often share private information, such as their emotions, photos, and locations, to interact with others. Sometimes, users may bind their credit cards to the social applications to enjoy the convenience of mobile payment. The target respondents of this study are the mobile social networking users in China. Sina and WeChat are selected as the platforms for testing the proposed model for two reasons. First, WeChat and Sina are the two most widely adopted mobile social applications. Their market shares show dominating advantages over other applications (Figure 2). Second, statistics show that no systematic differences between the behaviours on WeChat/Sina and on other social applications, such as Facebook and Twitter (CNNIC, 2015; Delzio, 2015). Therefore, data from WeChat and Sina are appropriate to test our models. Mobile phone numbers are mandatory for completing the registrations. Thus, they can be used to identify the accounts of WeChat and Sina users. In this study, we generated a set of random phone numbers (the detailed processes are shown in Appendix). The owners of these random phone numbers are the target respondents. Two test accounts were registered on Sina and WeChat. The targeted respondents were added by searching the randomly generated phone numbers. The hyperlinks of the questionnaires were sent through the test accounts. To encourage survey participation, 1) we noted that 5 Chinese dollars were guaranteed for each respondent who completed a qualified questionnaire and 2) we explained the purpose of this study in detail and promised to take the responsibility for any information misuse. The reward money was transferred to the qualified respondents through the "luck money" (also known as the "money in red envelope") function.

\section{[Insert Figure 2 here]}

Our measures were adapted from previous studies (details are shown in Table 1). Two rounds of pilot tests were conducted to detect potential biases in the questionnaire design. In the first pilot test, we used a convenience sample and received 30 valid responses. Extreme values were identified by descriptive statistics. Two items associated with self-esteem, one item associated with flow experience, and one item associated with monetary rewards in the original scales were dropped due to a lack of internal consistency. In the second pilot test, we used a random sample and received 97 valid responses. Examples of deceptions and misrepresentations were added and the items of self-disclosure honesty were re-described in a euphemistic way given that they had low response rates in the first pilot test. In the final survey, one item associated with self-disclosure honesty was dropped, and two control variables 
(privacy policy and law enforcement) were added. All survey items were based on a 7-point Likert scale ranging from 1=strongly disagree to $7=$ strongly agree.

\section{[Insert Table 1 here]}

\subsection{Respondents and Method for Data Analysis}

Having addressed all the issues revealed in the pilot tests, 1678 questionnaires were distributed and 1032 responses were received in the main survey. Overall, 492 responses from WeChat and 421 responses from Sina were qualified in the final analysis. The demographic characteristics of the respondents are reported in Table 2. Approximately $64.5 \%$ of the respondents are male users, and nearly $93.4 \%$ of the respondents are daily active users. The results were consistent with the statistics released by WeChat, which claims that the ratio between male users and female users is 2:1 and $94 \%$ of users log on to their account daily (Wechat, 2015). Therefore, the sample is quite representative.

\section{[Insert Table 2 here]}

Partial least squares (PLS) regression was used to test the models for two reasons. First, PLS simultaneously estimates the measurement models and structural models. Second, privacy concern in this study was a formative second-order construct composed of three first-order factors. Compared with covariance-based structural equation modelling (SEM), PLS is more appropriate in handling formative measures (Hair, Ringle, \& Sarstedt, 2011). The control variables included demographic statistics, such as gender, age, education, and monthly income. Service providers attempt to address the privacy concern of users by posting their privacy policy. A privacy policy explains the practices regarding the collection and use of customer information. Users' perceptions of privacy policy are positively related to self-disclosure (Andrade et al., 2002). Moreover, legal environment and prior experience involving privacy invasion may be associated with privacy protective behaviours. Therefore, three control variables were added, privacy policy, law enforcement, and privacy invasion experience, to avoid potential biases. We constructed the measure of perceptions of privacy policy using the following three items based on Zhao et al. (2012): "the mobile social media that I use provides detailed explanations of privacy policy," "the privacy policy clearly describes how service providers protect and use the personal information of users," and "the privacy policy clearly defines the privacy rights of users." We developed three items for law enforcement. The construct was created to measure the perceptions of law enforcement activities in privacy domain. Law enforcement is any system by which some members of society act in an organized manner to enforce the law by deterring, or punishing people who violate the rules that governing society (Wikipedia). Applied to privacy, we developed items to reflect users' perceptions of law enforcement activities under the risk of information misuse. The items were: "I believe the legal 
punishment of the information misuse could prevent privacy invasions," "I believe that service providers would be punished by law if my personal information was being used without my permission," and "the punishment of information misuse was deterrent to service providers."

\section{Data Analysis}

\subsection{Measurement Models}

\subsubsection{Reliability and Validity}

The constructs were assessed by examining their reliability and convergent and discriminant validity. In this study, privacy concern is a second-order formative construct and the rest (including the three first-order constructs PC-AWA, PC-COL, and $\mathrm{PC}-\mathrm{CON}$ ) are reflective constructs. The reliability of a reflective construct can be assessed by verifying its composite reliability and average variance extracted (AVE) (Fornell \& Larcker, 1981). Table 4 shows that all the composite reliabilities and AVEs values were higher than the suggested thresholds of 0.7 and 0.5 (Fornell \& Larcker, 1981). Therefore, the constructs exhibit high reliability.

Convergent validities can be assessed by determining whether the loadings of items on their respective constructs are sufficiently high. To ensure adequate discriminant validity, the loadings of items on their respective constructs must be higher than those on other constructs. The loadings and cross-loadings are presented in Table 3. The loadings of items on their respective constructs were higher than 0.7 (Nunnelly, 1978), and these loadings were higher than the cross-loadings.

\section{[Insert Table 3 here]}

An alternative method was used to evaluate discriminant validity. To ensure sufficient discriminant validity, the square roots of the average variances extracted (AVE) of any latent variables should be higher than the correlations shared between the latent variable and other latent variables (Barclay, Higgins, \& Thompson, 1995). The data shown in Table 4 satisfy this requirement, indicating that each reflective construct is more strongly related to its own measures than to the rest of the constructs. These results suggest that the constructs exhibit adequate convergent and discriminant validities.

\section{[Insert Table 4 here]}

Given that privacy concern was operationalized as a second-order formative construct, Edwards' (2001) adequacy coefficient $\left(\mathrm{R}_{\mathrm{a}}{ }^{2}\right)$ was used to test the validity. Adequacy coefficient $\left(\mathrm{R}_{\mathrm{a}}{ }^{2}\right)$ can be calculated by summing the squared correlations between each first-order construct and the focal construct, and then dividing by the number of sub-dimensions ${ }^{1}$. The threshold for $\mathrm{R}_{\mathrm{a}}{ }^{2}$ is 0.5 (Edwards, 2001). In the current study, the $\mathrm{R}_{\mathrm{a}}{ }^{2}$ for privacy concern was 0.641 , indicating high validity. The

\footnotetext{
${ }^{1}$ See details in Edwards (2001, p. 163).
} 
internal consistency reliability test for privacy concern was not conducted because items in the informative model might be uncorrelated with one another.

\subsubsection{Common Method Bias}

A series of tests was conducted for common method bias as our data were drawn from a single source. First, Harman's one-factor test was conducted (Podsakoff, MacKenzie, Lee, \& Podsakoff, 2003). This test requires an exploratory, unrotated factor analysis on all of the items. Common method variance is not present if items load on multiple factors and one factor does not account for most of the variance. The factor analysis resulted in nine factors with eigenvalues greater than one, which explain $84 \%$ of the variance, with the largest factor accounting for only $18 \%$.

Second, following Podsakoff et al. (2003), a two-step confirmatory factor analysis (CFA) was conducted. In the first step, an 11-factor model was estimated. The eleven factors were: self-disclosure intention, self-disclosure honesty, monetary rewards, social rewards, privacy concern-awareness (PC-AWA), privacy concern-collection (PC-COL), privacy concern-control (PC-CON), application compatibility, application reputation, self-esteem, and flow experience. Each of the 43 items was restricted to being an indicator of their respective latent factor. For example, items AWA1, AWA2, and AWA3 were restricted to link with the construct PC-AWA only.The fit indices of the first model were $\alpha^{2} / d f=1.44, \mathrm{CFI}=0.965, \mathrm{GFI}=0.912 ; \mathrm{AGFI}=0.879$, and RMSEA $=0.023$. All these indices satisfied the recommended thresholds ${ }^{2}$ and indicated a good fit of the data. In the second step, in addition to the eleven factors examined in the first model, one additional factor was added to represent the unmeasured common method. Each of the 43 items was allowed to load on its respective theoretical factor, and all were allowed to load on the additional methods factor, which was constrained to be uncorrelated with the other eleven factors. For example, items AWA1, AWA2, and AWA3 were allowed to link with the construct of PC-AWA and the additional factor, namely, common method variance. The fit indices $\left(\alpha^{2} / d f=1.45, \mathrm{CFI}=0.965, \mathrm{GFI}=0.911, \mathrm{AGFI}=0.879, \mathrm{RMSEA}=0.023\right)$ of the second model were largely identical to those of the first one. In addition, the Chi-square test comparing the first model with the second model indicated that the difference between the two models was insignificant $(\alpha(2)=0.01, p=n . s$.). Thus, these tests provide evidence that common method bias was not a major concern for this study.

\subsection{Structural Models}

The results of the structural models are presented in Figure 3. The coefficients of the control variables are shown in Table 5 . The compatibility of mobile applications was positively related to social rewards $(\beta=0.27, p<0.01)$, and the reputation of mobile applications was negatively related to privacy concern $(\beta=-0.21, p<0.01)$, lending

2 The fit index criteria for an acceptable model were as follows: below 3 for $\alpha^{2} / \mathrm{df}$, below 0.06 for root mean square error of approximation [RMSEA], above 0.80 for adjusted goodness-of-fit [AGFI], above 0.90 for normed fit index [NFI], above 0.95 for comparative fit index [CFI], above 0.90 for goodness-of-fit [GFI], and above 0.90 for Tucker-Lewis index [TLI] (Hu \& Bentler, 1999). 
supports for Hypothesis 1 and Hypothesis 3. Hypothesis 2 was not justified because the relationship between application reputation and social rewards was insignificant. Self-esteem was positively related to privacy concerns $(\beta=0.19, p<0.05)$. Therefore, Hypothesis 4 was supported. Consistent with our predictions, flow experience was positively related to social rewards $(\beta=0.32, p<0.001)$ but negatively related to privacy concern $(\beta=-0.44, p<0.001)$, thus supporting Hypothesis 5 and Hypothesis 6.

The model of self-disclosure intention explained $48 \%$ of the total variance. Monetary rewards $(\beta=0.21, p<0.01)$ and social rewards $(\beta=0.46, p<0.01)$ positively predicted self-disclosure intention, whereas privacy concern negatively predicted self-disclosure intention $(\beta=-0.14, p<0.001)$. Therefore, Hypothesis 7,9 , and 11 were supported. The model of self-disclosure honesty explained $37 \%$ of the total variance. The path coefficient between monetary rewards and self-disclosure honesty was insignificant. Therefore, Hypothesis 8 was not supported. Social rewards positively affected self-disclosure honesty $(\beta=0.58, p<0.001)$, whereas privacy concern negatively affected self-disclosure honesty $(\beta=-0.25, p<0.01)$. These results provide support for Hypothesis 10 and Hypothesis 12.

\section{[Insert Figure 3 here]}

\section{[Insert Table 5 here]}

The model results show that the coefficient of social rewards was larger than the coefficients of monetary rewards and privacy concerns. To investigate this finding further, we examined whether the differences between these coefficients are significant. We calculated the unbiased beta weights for each coefficient and conducted a t-test for each pairwise comparison (Dawson \& Richter, 2006). The results are reported in Table 6, which shows that the coefficient of social rewards was significantly different from the coefficients of monetary rewards and privacy concerns. These findings suggest that users of social media place more weight on social rewards than on monetary rewards and privacy concerns.

\section{[Insert Table 6 here]}

\section{Discussions and Conclusion}

\subsection{Discussion of the Findings}

Ten out of twelve hypotheses are supported (details are shown in Table 7). We found that the characteristics of service providers and the interpersonal difference of users influence the perceptions of privacy concerns and social rewards. Application reputation eases users' concern regarding privacy invasion, whereas application compatibility strengthens the perceptions of social rewards. The flow experience of users weakens the perception of privacy concern and strengthens the perception of social rewards. The coefficient of application reputation on social rewards is 
insignificant. Thus, Hypothesis 2 is not supported. The logic presented above indicates that high reputation leads to a large number of active users, thereby increasing the possibility of making new friends. A possible explanation is that the development of new friendships does not necessarily lead to high social rewards. The positive relationship between monetary rewards and self-disclosure honesty was not found. Study has found that the costs of dishonesty are determined by the likelihood of the dishonest behaviours getting caught and the magnitude of subsequent punishment (Becker, 1968). Monetary rewards may not be positivity related to self-disclosure honesty because the authenticity of the information disclosed on social media is quite difficult to justify (Shalvi, Eldar, \& Bereby-Meyer, 2012). These findings confirm that in the context of mobile social networking, social rewards and monetary rewards differ in predicting users' privacy protective behaviours. Social rewards and monetary rewards are positively related to self-disclosure intention. Meanwhile users place more weight on social rewards than on monetary rewards. Moreover, only social rewards positively predict self-disclosure honesty.

[Insert Table 7 here]

\subsection{Theoretical Implications}

This paper provides several contributions. First, the current study extends the existing self-disclosure literature by exploring the antecedents of self-disclosure honesty. User-generated data provide rich opportunities for business and academic scholars (Erevelles et al., 2016; Gandomi \& Haider, 2015). Therefore, a large number of researchers direct their attentions toward self-disclosure intention (Posey et al., 2010; Wang et al., 2016; Zhao et al., 2012). A basic assumption made in these studies is that users are completely sincere when disclosing personal information. However, the assumption does not hold at all times. Misrepresentation and information manipulation commonly occur as users are willing to convey positive images to others (Krasnova et al., 2010). Respondents participating in a survey may disclose inaccurate personal information to gain the rewards of the survey while protecting their privacy. Inaccurate customer data cause substantial social and economic effects. For instance, inaccurate customer information may mislead managers' strategic decisions (Mason \& Harris, 2005) and distort the findings of marketing scholars (Robertshaw \& Marr, 2006). Moreover, the authenticity of information is critical in specific contexts, such as location-based service and healthcare social networking. Understanding the antecedents of self-disclosure honesty provides guidelines for service providers to obtain accurate customer data.

Second, this study enriches the privacy calculus model by differentiating the roles played by social rewards and monetary rewards in privacy protective behaviours. We found that both social and monetary rewards positively predict self-disclosure intention, whereas only social rewards positively predict self-disclosure honesty. Previous studies on the privacy calculus models focus on the signal source of rewards. For example, Premazzi et al. (2010) emphasized the role of monetary rewards in e-commerce, and other studies stressed on the social rewards obtained in social 
networking (Jiang et al., 2013; Z. Liu et al., 2016). Individuals protect their privacy by reservation, deception, or dissimulation (Acquisti et al., 2015). Social and monetary rewards differ in the ways they predict privacy protective behaviours. For example, to gain emotional support, individuals may reveal their inner desires. And individuals may provide superficial self-disclosure for monetary rewards. Therefore, differentiating the roles of social and monetary rewards provides a comprehensive understanding of the privacy calculus model.

Third, this study advances the understanding on the privacy calculus model by clarifying the influence of interpersonal difference and characteristics of service providers on privacy trade-off. Users' privacy protective behaviours cannot be fully predicted without considering interpersonal difference and contextual settings. Individuals' perceptions of privacy concern and rewards vary with interpersonal difference and contextual settings. For example, adults have a much higher reward threshold for self-disclosure than teenagers (Youn, 2009). Individuals who are highly sensitive to personal information develop substantial privacy concerns regarding a given probability of privacy invasion (Korzaan \& Boswell, 2008). When immersed in a certain type of activity, individuals ignore or downplay the negative effects of that activity (Partington et al., 2009). Therefore, potential value exists in understanding the influence of interpersonal difference and characteristics of service providers on privacy trade-off.

\subsection{Managerial Implications}

The present study offers several practical insights for businesses. Service providers are advised to adopt respective segmentation and targeting strategies based on the interpersonal difference of their users. Flow experience weakens the perceptions of privacy concern and magnifies the perceptions of social rewards. Businesses may take advantage of this knowledge and strive to maximize the flow experience of customers. For example, service providers can offer a user-friendly design to create easy-to-use applications and enrich their functions. Self-esteem is positively related to privacy concern. Service providers can offer different levels of privacy policies and let the users select by themselves. For example, high self-esteem users are more likely to select conservative policies such as providing a double verification process before log in, giving permission when others access personal profiles, and making personal information automatically invisible to strangers.

Moreover, social media operators can undertake significant efforts to raise their brand awareness as reputation eases privacy concern. Although every social media outlet claims that privacy protection is its priority, users place high trust on renowned applications (King-Casas et al., 2005). Users may better perceive social rewards if an application is consistent with their existing values, lifestyles, and needs. A mobile application may be perceived useful and convenience if it fits the users' existing values, lifestyles, and needs. Users are more likely to disclose truthful information to the applications which are useful and convenience. For example, WeChat is only a chatting application in the early years. Given that mobile payment has become popular among the young generation, WeChat introduced the WeChat Pay. WeChat Pay requests users to have credit card attached to their WeChat accounts and they can 
then send money to friends, request money from friends, pay bills and even pay in stores. WeChat Pay is now one of the most widely used functions and keep credit card information of more than 200 million users (Russell, 2015).

Social media operators encourage users to disclose personal information because large amounts of customer data can improve their service quality (Fan \& Gordon, 2014). Caution should therefore be taken because users may disclose inaccurate information to protect their privacy. Social rewards positively predict disclosure honesty. The coefficients suggest that, at least in the context of mobile social networking, customers place more weight on social rewards than on monetary rewards. Social media providers can undertake additional efforts to create salient and distinct social rewards. For example, social networking providers are encouraged to make potential users aware that their applications are full of opportunities such as: making new friends with diverse backgrounds, finding someone who has common interests, and joining certain social groups. Users who become immersed in the social rewards offered by service providers may become very willing to disclose truthful information.

\subsection{Limitations and Future Directions}

This study has several limitations that can be examined further. First, privacy protective behaviours are not fully captured in the proposed model. Posey et al. (2010) argued that individuals' privacy protective behaviours have four dimensions, namely, intention, honesty, amount, and depth. Individuals faced with potential privacy risks may engage in superficial self-disclosure and hide their inner emotions. A deep understanding of customers helps service providers to understand what users want and how they make choices (Simonson, 1993). Thus, the antecedents of self-disclosure depth deserve further investigation.

Second, the setting in the present study challenges the prominent role of social rewards. This study was conducted in China, which is a country with a collectivist culture (Hofstede, Hofstede, \& Minkov, 1991). Respondents in a collectivist culture pay high attentions to social relationships. Perceptions regarding privacy differ significantly across cultures. Specifically, people differ substantially in how much they care about privacy and what information they treat as private (Nissenbaum, 2009). Acquisti et al. (2015) asserted that "Americans are reputed to be more open about sexual matters than are the Chinese, whereas the latter are more open about financial matters, such as income, cost of home, and possessions" (p. 513). Whether our findings hold in other settings must be examined in future research.

Third, the self-reported nature of the measures in this study fails to capture the actual privacy protective behaviours. Behaviour intention is widely used as a proxy for actual behaviours in IS studies (Malhotra, Kim, \& Agarwal, 2004); however, the correlation between behaviour intention and actual behaviours is confounded by various factors. Individuals' recall may not completely reflect their actual behaviours because the rules based on which people manage their privacy vary by situations and are learned over time (Acquisti et al., 2015). For instance, people are typically comfortable sharing secrets only with close friends, but they may sometimes reveal 
personal information to strangers on a plane. Moreover, self-interpretation may sometimes be inconsistent with actual behaviours because individuals desire to portray them in a generally favourable light (Holden \& Millett, 2005). Therefore, further research can extend the current model to actual self-disclosure behaviours.

\section{Appendix}

\section{Backgrounds of mobile phone numbers in China}

1. Mobile phone numbers in China consist of 11 digits. The first three numbers represent the operator code. The next four numbers represent the city-level area code. Take a mobile phone number $138 \underline{0210} \underline{1234}$ for example; the first three numbers 138 indicating that the operator is China Mobile. The following four-digit city code 0210 represents Shanghai City.

2. China has three mobile phone operators: China Mobile, China Unicom, and China Telecom. Each mobile phone operator has its codes (Table 8). The market shares of China Mobile, China Unicom, and China Telecom are 61\%, 24\%, and 15\%, respectively (Kantar, 2015). The approximate ratio is $3: 1: 1$.

[Insert Table 8 here]

\section{Process of generating random mobile phone numbers}

Generating random mobile phone numbers involves three main steps.

First, considering the ratio of their market shares, we randomly selected three operator codes of China Mobile, one operator code of China Unicom, and one operator code of China Telecom. The randomly selected operator codes comprise the first three numbers.

Second, following the survey conducted by China Internet Network Information Center (CNNIC, 2015), we geographically divided China into seven regions in this study (Figure 4). For each region, we randomly select two cities. Thus, 14 cities were targeted. The codes of these cities comprised the middle four numbers.

\section{[Insert Figure 4 here]}

Third, for each city code, we generated 100 four-digit random numbers. These random four-digit numbers comprised the last four numbers. Therefore, $5 \times 14 \times 100=7000$ random mobile phone numbers were generated. All the randomly generated mobile phone numbers are available upon request. 


\section{Reference}

Acquisti, A., Brandimarte, L., \& Loewenstein, G. (2015). Privacy and human behavior in the age of information. Science, 347(6221), 509-514.

Agarwal, R., \& Karahanna, E. (2000). Time flies when you're having fun: Cognitive absorption and beliefs about information technology usage. MIS Quarterly, 665-694.

Andrade, E. B., Kaltcheva, V., \& Weitz, B. (2002). Self-disclosure on the web: the impact of privacy policy, reward, and company reputation. NA-Advances in Consumer Research Volume 29.

Argo, J. J., White, K., \& Dahl, D. W. (2006). Social comparison theory and deception in the interpersonal exchange of consumption information. Journal of Consumer Research, 33(1), 99-108.

Awad, N. F., \& Krishnan, M. S. (2006). The personalization privacy paradox: an empirical evaluation of information transparency and the willingness to be profiled online for personalization. MIS Quarterly, 13-28.

Bansal, G., \& Gefen, D. (2010). The impact of personal dispositions on information sensitivity, privacy concern and trust in disclosing health information online. Decision Support Systems, 49(2), 138-150.

Barclay, D., Higgins, C., \& Thompson, R. (1995). The partial least squares (PLS) approach to causal modeling: Personal computer adoption and use as an illustration. Technology Studies, 2(2), 285-309.

Bargh, J. A., McKenna, K. Y., \& Fitzsimons, G. M. (2002). Can you see the real me? Activation and expression of the "true self" on the Internet. Journal of Social Issues, 58(1), 33-48.

Bearden, W. O., Hardesty, D. M., \& Rose, R. L. (2001). Consumer self-confidence: Refinements in conceptualization and measurement. Journal of Consumer Research, 28(1), 121-134.

Becker, G. S. (1968). Crime and punishment: An economic approach The Economic Dimensions of Crime (pp. 13-68): Springer.

Ben-Ze'ev, A. (2003). Privacy, emotional closeness, and openness in cyberspace. Computers in Human Behavior, 19(4), 451-467.

Błachnio, A., Przepiorka, A., \& Pantic, I. (2016). Association between Facebook addiction, self-esteem and life satisfaction: a cross-sectional study. Computers in Human Behavior, 55, 701-705.

Campbell, A. J. (1997). Relationship marketing in consumer markets: A comparison of managerial and consumer attitudes about information privacy. Journal of Interactive Marketing, 11(3), 44-57.

Chang, M. K., Cheung, W., \& Tang, M. (2013). Building trust online: Interactions among trust building mechanisms. Information \& Management, 50(7), 439-445.

CNNIC. (2015). Annual Report of the Research on Social Media Users, from http://www.cnnic.net.cn/hlwfzyj/hlwxzbg/

Crocker, J., Thompson, L. L., McGraw, K. M., \& Ingerman, C. (1987). Downward comparison, prejudice, and evaluations of others: effects of self-esteem and threat. Journal of Personality and Social Psychology, 52(5), 907.

Csikszentmihalyi, M. (1990). Flow. The Psychology of Optimal Experience. New York (HarperPerennial) 1990.

Dawson, J. F., \& Richter, A. W. (2006). Probing three-way interactions in moderated multiple regression: development and application of a slope difference test. Journal of Applied Psychology, 91(4), 917.

Debatin, B., Lovejoy, J. P., Horn, A. K., \& Hughes, B. N. (2009). Facebook and online privacy: Attitudes, 
behaviors, and unintended consequences. Journal of Computer - Mediated Communication, 15(1), 83-108.

Deci, E. L., Koestner, R., \& Ryan, R. M. (1999). A meta-analytic review of experiments examining the effects of extrinsic rewards on intrinsic motivation. Psychological Bulletin, 125(6), 627.

Delzio, S. (2015). Facebook and Twitter User Behavior Changes: New Research, from http://www.socialmediaexaminer.com/facebook-and-twitter-user-behavior-changes-new-res earch/

Deng, L., Turner, D. E., Gehling, R., \& Prince, B. (2010). User experience, satisfaction, and continual usage intention of IT. European Journal of Information Systems, 19(1), 60-75.

Dinev, T., \& Hart, P. (2006). An extended privacy calculus model for e-commerce transactions. Information Systems Research, 17(1), 61-80.

Doney, P. M., \& Cannon, J. P. (1997). An examination of the nature of trust in buyer-seller relationships. The Journal of Marketing, 35-51.

Eastlick, M. A., Lotz, S. L., \& Warrington, P. (2006). Understanding online B-to-C relationships: An integrated model of privacy concerns, trust, and commitment. Journal of Business Research, 59(8), 877-886.

Edwards, J. R. (2001). Multidimensional constructs in organizational behavior research: An integrative analytical framework. Organizational Research Methods, 4(2), 144-192.

Ellison, N. B., Vitak, J., Gray, R., \& Lampe, C. (2014). Cultivating social resources on social network sites: Facebook relationship maintenance behaviors and their role in social capital processes. Journal of Computer - Mediated Communication, 19(4), 855-870.

Engeser, S., \& Rheinberg, F. (2008). Flow, performance and moderators of challenge-skill balance. Motivation and Emotion, 32(3), 158-172.

Erevelles, S., Fukawa, N., \& Swayne, L. (2016). Big Data consumer analytics and the transformation of marketing. Journal of Business Research, 69(2), 897-904.

Facebook. (2016). Statistics, from http://newsroom.fb.com/company-info/

Fan, W., \& Gordon, M. D. (2014). The power of social media analytics. Communications of the ACM, 57(6), 74-81.

Fershtman, C., \& Weiss, Y. (1998). Social rewards, externalities and stable preferences. Journal of Public Economics, 70(1), 53-73.

Ford, R. C., \& Richardson, W. D. (1994). Ethical decision making: A review of the empirical literature. journal of Business Ethics, 13(3), 205-221.

Fornell, C., \& Larcker, D. F. (1981). Evaluating structural equation models with unobservable variables and measurement error. Journal of Marketing Research, 39-50.

Gandomi, A., \& Haider, M. (2015). Beyond the hype: Big data concepts, methods, and analytics. International Journal of Information Management, 35(2), 137-144.

Gefen, D., Karahanna, E., \& Straub, D. W. (2003). Trust and TAM in online shopping: an integrated model. MIS Quarterly, 27(1), 51-90.

Gillenson, M. L., \& Sherrell, D. L. (2002). Enticing online consumers: an extended technology acceptance perspective. Information \& Management, 39(8), 705-719.

Hair, J. F., Ringle, C. M., \& Sarstedt, M. (2011). PLS-SEM: Indeed a silver bullet. Journal of Marketing Theory and Practice, 19(2), 139-152.

Hann, I.-H., Hui, K.-L., Lee, S.-Y. T., \& Png, I. P. (2007). Overcoming online information privacy concerns: An information-processing theory approach. Journal of Management Information Systems, 
24(2), 13-42.

Hess, T. J., McNab, A. L., \& Basoglu, K. A. (2014). Reliability Generalization of Perceived Ease of Use, Perceived Usefulness, and Behavioral Intentions. MIS Quarterly, 38(1), 1-28.

Hoffman, D. L., \& Novak, T. P. (1996). Marketing in hypermedia computer-mediated environments: Conceptual foundations. The Journal of Marketing, 50-68.

Hoffman, D. L., Novak, T. P., \& Peralta, M. (1999). Building consumer trust online. Communications of the ACM, 42(4), 80-85.

Hofstede, G., Hofstede, G. J., \& Minkov, M. (1991). Cultures and organizations: Software of the mind (Vol. 2): Citeseer.

Holden, S. H., \& Millett, L. I. (2005). Authentication, privacy, and the federal e-government. The Information Society, 21(5), 367-377.

Hsu, C.-L., \& Lu, H.-P. (2004). Why do people play on-line games? An extended TAM with social influences and flow experience. Information \& Management, 41(7), 853-868.

Hu, L. t., \& Bentler, P. M. (1999). Cutoff criteria for fit indexes in covariance structure analysis: Conventional criteria versus new alternatives. Structural Equation Modeling: a multidisciplinary journal, 6(1), 1-55.

Jiang, Z., Heng, C. S., \& Choi, B. C. (2013). Research note-privacy concerns and privacy-protective behavior in synchronous online social interactions. Information Systems Research, 24(3), 579-595.

Külcü, Ö., \& Henkoğlu, T. (2014). Privacy in social networks: An analysis of Facebook. International Journal of Information Management, 34(6), 761-769.

Kantar. (2015). China IT News, from http://www.199it.com/archives/371806.html

King-Casas, B., Tomlin, D., Anen, C., Camerer, C. F., Quartz, S. R., \& Montague, P. R. (2005). Getting to know you: reputation and trust in a two-person economic exchange. Science, 308(5718), 78-83.

Korzaan, M. L., \& Boswell, K. T. (2008). The influence of personality traits and information privacy concerns on behavioral intentions. Journal of Computer Information Systems, 48(4), 15-24.

Koufaris, M. (2002). Applying the technology acceptance model and flow theory to online consumer behavior. Information Systems Research, 13(2), 205-223.

Krasnova, H., Spiekermann, S., Koroleva, K., \& Hildebrand, T. (2010). Online social networks: why we disclose. Journal of Information Technology, 25(2), 109-125.

Lawler, E. J., \& Thye, S. R. (1999). Bringing emotions into social exchange theory. Annual Review of Sociology, 217-244.

Lin, H.-F. (2011). An empirical investigation of mobile banking adoption: The effect of innovation attributes and knowledge-based trust. International Journal of Information Management, 31(3), 252-260.

Liu, C., Marchewka, J. T., Lu, J., \& Yu, C.-S. (2005). Beyond concern-a privacy-trust-behavioral intention model of electronic commerce. Information \& Management, 42(2), 289-304.

Liu, Z., Min, Q., Zhai, Q., \& Smyth, R. (2016). Self-disclosure in Chinese micro-blogging: A social exchange theory perspective. Information \& Management, 53(1), 53-63.

Mäntymäki, M., \& Salo, J. (2015). Why do teens spend real money in virtual worlds? A consumption values and developmental psychology perspective on virtual consumption. International Journal of Information Management, 35(1), 124-134.

Malhotra, N. K., Kim, S. S., \& Agarwal, J. (2004). Internet users' information privacy concerns (IUIPC): 
The construct, the scale, and a causal model. Information Systems Research, 15(4), 336-355.

Mason, K., \& Harris, L. C. (2005). Pitfalls in evaluating market orientation: an exploration of executives' interpretations. Long Range Planning, 38(4), 373-391.

Mazar, N., \& Ariely, D. (2006). Dishonesty in everyday life and its policy implications. Journal of Public Policy \& Marketing, 25(1), 117-126.

Nissenbaum, H. (2009). Privacy in context: Technology, policy, and the integrity of social life: Stanford University Press.

Nunnelly. (1978). Psychometric theory 2nd ed: New York: McGraw-Hill.

Oh, H. J., Ozkaya, E., \& LaRose, R. (2014). How does online social networking enhance life satisfaction? The relationships among online supportive interaction, affect, perceived social support, sense of community, and life satisfaction. Computers in Human Behavior, 30, 69-78.

Ozturk, A. B., Bilgihan, A., Nusair, K., \& Okumus, F. (2016). What keeps the mobile hotel booking users loyal? Investigating the roles of self-efficacy, compatibility, perceived ease of use, and perceived convenience. International Journal of Information Management.

Partington, S., Partington, E., \& Olivier, S. (2009). The dark side of flow: A qualitative study of dependence in big wave surfing. Sport Psychologist. 23 (2).

Pierce, J. L., \& Gardner, D. G. (2004). Self-esteem within the work and organizational context: A review of the organization-based self-esteem literature. Journal of Management, 30(5), 591-622.

Podsakoff, P. M., MacKenzie, S. B., Lee, J.-Y., \& Podsakoff, N. P. (2003). Common method biases in behavioral research: a critical review of the literature and recommended remedies. Journal of Applied Psychology, 88(5), 879.

Posey, C., Lowry, P. B., Roberts, T. L., \& Ellis, T. S. (2010). Proposing the online community self-disclosure model: the case of working professionals in France and the UK who use online communities. European Journal of Information Systems, 19(2), 181-195.

Premazzi, K., Castaldo, S., Grosso, M., Raman, P., Brudvig, S., \& Hofacker, C. F. (2010). Customer information sharing with e-vendors: The roles of incentives and trust. International Journal of Electronic Commerce, 14(3), 63-91.

Robertshaw, G., \& Marr, N. (2006). An empirical measure of the availability, completeness and reliability of voluntarily disclosed personal information for direct marketing purposes. Journal of Financial Services Marketing, 11(1), 85-94.

Russell, J. (2015). Tencent's Wechat Messaging App Reaches 200M Users On Its Payment Service from https://techcrunch.com/2015/11/10/tencents-wechat-messaging-app-reaches-200m-users-o n-its-payments-service/?ncid=rss

Sanchez-Franco, M. J. (2006). Exploring the influence of gender on the web usage via partial least squares. Behaviour \& Information Technology, 25(1), 19-36.

Shalvi, S., Eldar, O., \& Bereby-Meyer, Y. (2012). Honesty requires time (and lack of justifications). Psychological science, 23(10), 1264-1270.

Simonson, I. (1993). Get closer to your customers by understanding how they make choices. California Management Review, 35(4), 68-84.

Tidwell, L. C., \& Walther, J. B. (2002). Computer - mediated communication effects on disclosure, impressions, and interpersonal evaluations: Getting to know one another a bit at a time. Human Communication Research, 28(3), 317-348.

Twitter. (2015). 10 Remarkable Twitter Statistics for 2015, from 
http://lorirtaylor.com/twitter-statistics-2015/

Wang, T., Duong, T. D., \& Chen, C. C. (2016). Intention to disclose personal information via mobile applications: A privacy calculus perspective. International Journal of Information Management, 36(4), 531-542.

Wechat. (2015). WeChat User Global Report 2015, from https://www.linkedin.com/pulse/wechat-user-global-report-2015-alexis-bonhomme

Xu, H., Teo, H.-H., Tan, B. C., \& Agarwal, R. (2012). Research note-effects of individual self-protection, industry self-regulation, and government regulation on privacy concerns: a study of location-based services. Information Systems Research, 23(4), 1342-1363.

Youn, S. (2009). Determinants of online privacy concern and its influence on privacy protection behaviors among young adolescents. Journal of Consumer Affairs, 43(3), 389-418.

Zhao, L., Lu, Y., \& Gupta, S. (2012). Disclosure intention of location-related information in location-based social network services. International Journal of Electronic Commerce, 16(4), 53-90. 


\section{Figure 1 Research Model}

Characteristics of Service Providers

Privacy Trade-off

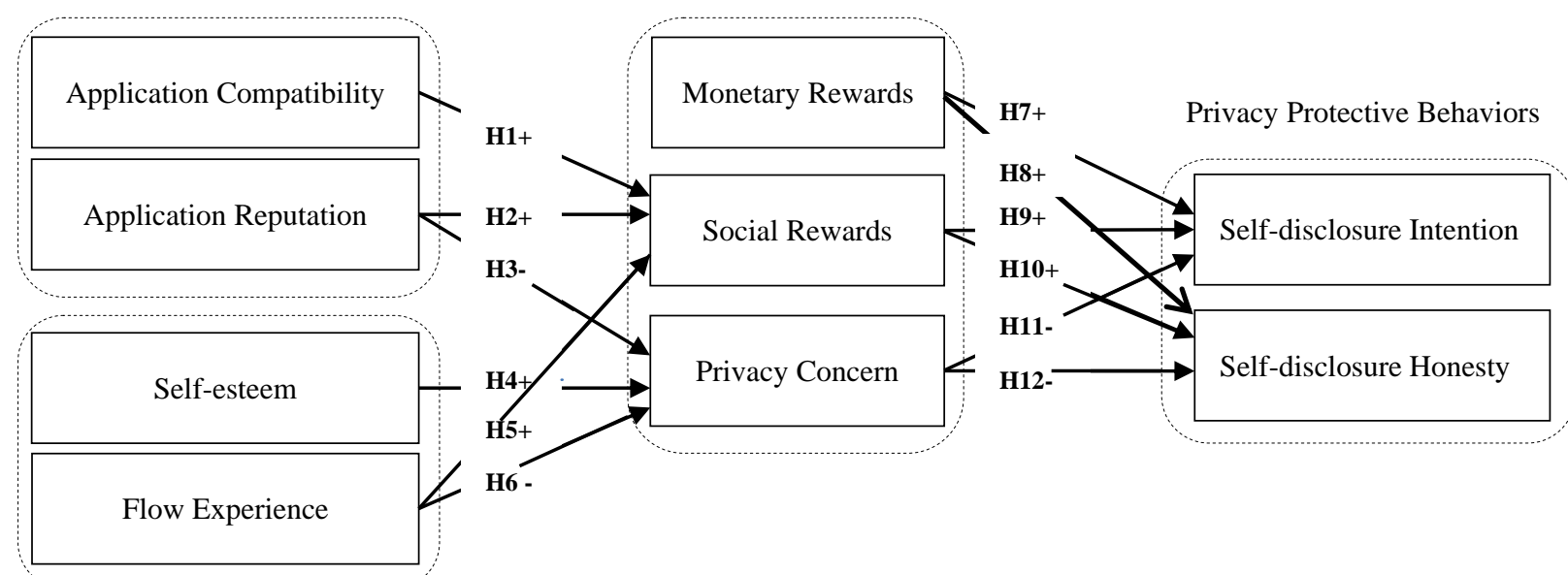

Interpersonal Difference

Fig 2 Market Shares of Mobile Social Media in China

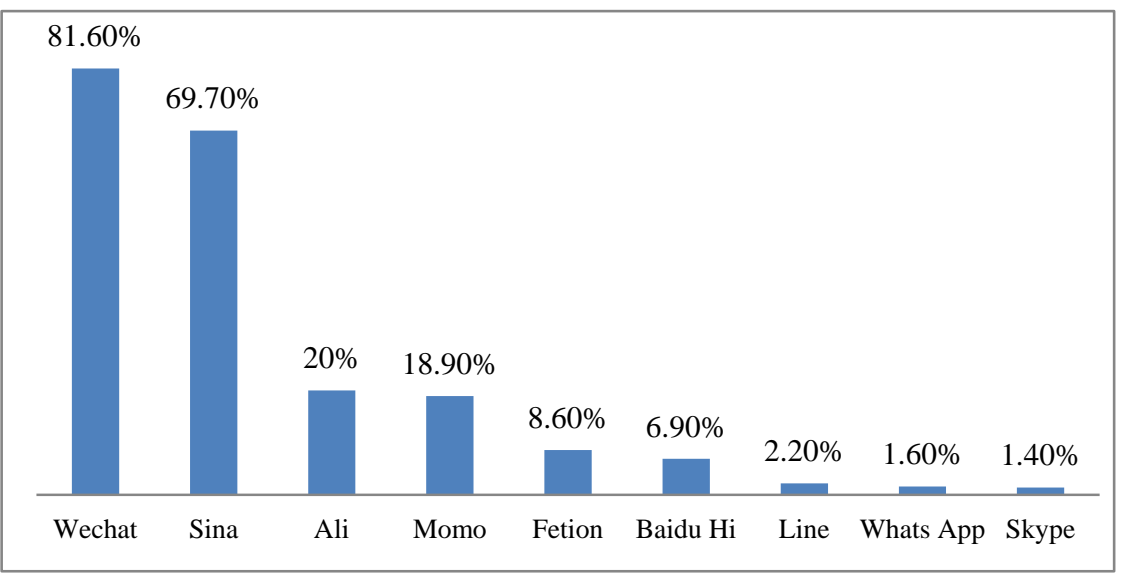

Note: Data were drawn from the 2015 Annual Report of Social Media Users in China, available at http://www.cnnic.net.cn/hlwfzyj/hlwxzbg/. 


\section{Figure 3 Model Results}

Characteristics of Service Providers
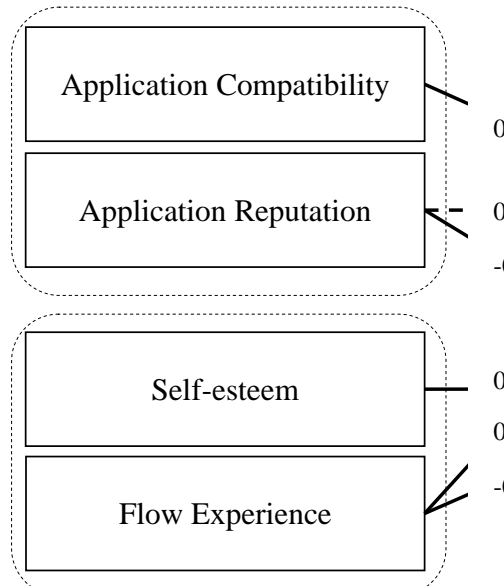

0.19

$-0.44^{* * *}$

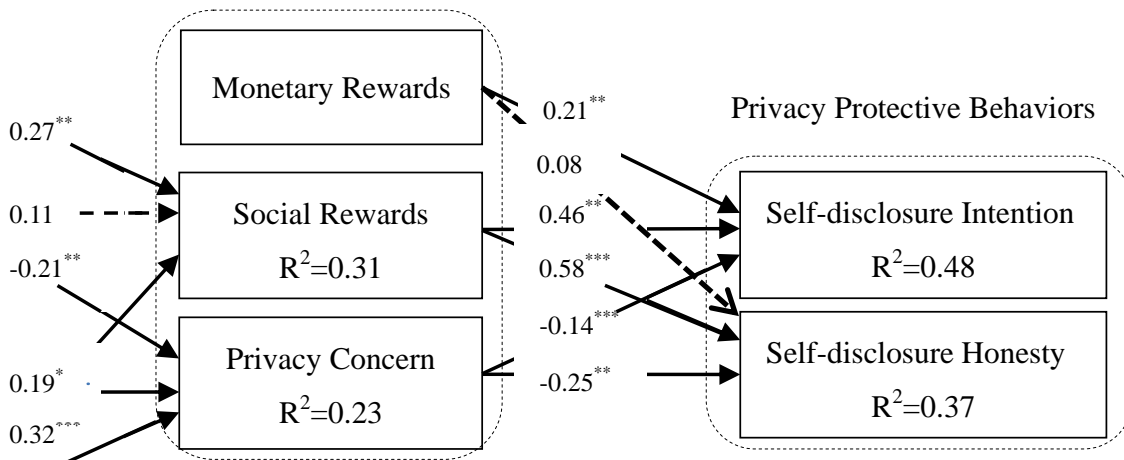

Privacy Trade-off

Interpersonal Difference

$*_{p}<0.05, * *_{p}<0.01, * * * p<0.001$ (two-tailed test). 
Figure 4 Seven Regions of China

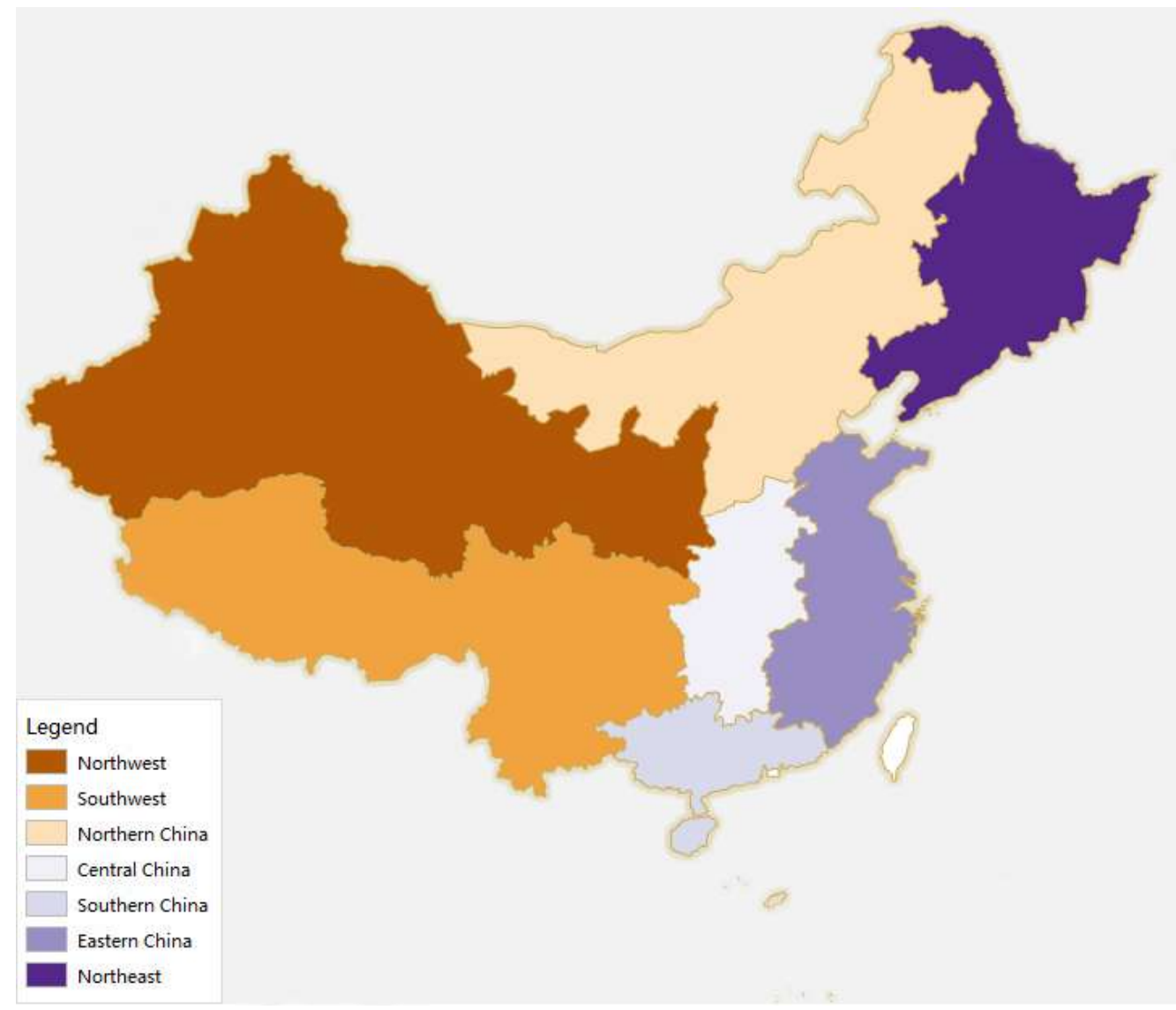




\section{Table 1 Measurement of the Constructs}

\begin{tabular}{ll}
\hline Constructs and Items & Sources \\
\hline Self-Esteem & Adapted from Greenberger et al. (2003)
\end{tabular}

SE1 I am a person with self-value

SE2 I have many good qualities.

SE3 I can make things well as others

SE4 There is nothing for me to be proud of

SE5 I am confident with myself

Flow

Developed from Hsu \& Lu (2004).

FL1 I frequently login on mobile social network unconsciously

FL2 I feel time passes quickly while using mobile social networks

FL3 I usually ignore other things when using mobile social networks

\section{Application Reputation}

Developed from Doney \& Cannon (1997)

AR1 The social application which I use is popular.

AR2 The social application which I use is widely recognized.

AR3 The social application which I use has good reputation.

Application Compatibility

Adapted from Chen \& Hung (2010)

AC1 Using mobile social applications fits my values.

AC2 Using mobile social applications fits my current needs.

AC3 Using mobile social applications fits my previous experiences.

Privacy Concern

Adapted from Malhotra et al. (2004)

\section{Awareness}

AWA1 I am confused when asked for personal information.

AWA2 I always think twice when asked for personal information.

AWA3 I am worried for providing personal information.

\section{Collection}

COL1. Service providers should open the process and intention when gathering personal information.

COL2 The abuse of personal information should be limited.

COL3 It is vital to know how my personal information is being used.

\section{Control}

CON1 I should be authorized to totally control my personal information.

CON2 Controlling personal information is an important aspect of privacy perception of users.

CON3 I would feel a privacy invasion when my control of personal information decreases.

\section{Social Rewards}

Developed from Mohamed \& Ahmad

SR1 Self-disclosure may help to establish relationship with my friends.

SR2 Self-disclosure may help to gain socio-emotional support from others

SR3 Self-disclosure may help me joining in some social groups.

\section{Monetary Rewards}

Developed from Zhao et al. (2012)

MR1 I am willing to self-disclosure if having the chance to get coupons.

MR2 I am willing to self-disclosure if discounts and promotion deals are offered

MR3 I am willing to self-disclosure if compensated with sufficient monetary rewards. 
SDI1 I am willing to self-disclosure when using mobile social applications in the future.

SDI2 I will probably disclose topics about myself if necessary.

SDI3 I will likely disclose my personal information if necessary.

Self-disclosure Honesty

Developed from Jiang et al. (2013) and

Posey et al. (2010)

SDH1 I may lie about myself when using mobile social applications.

SDH2 I may give a false impression about myself when using mobile social applications.

SDH3 I always feel completely sincere when I reveal my own feelings and experiences.

SDH4 My self-disclosures are completely accurate reflections of who I really am.

SDH5 My statements about my own feelings and emotions are accurate self-perceptions. 
Table 2 Demographic Statistics of Respondents (N=913)

\begin{tabular}{|c|c|c|c|}
\hline Variables & Levels & Count & Percentage \\
\hline \multirow[t]{2}{*}{ Gender } & Male & 589 & 64.5 \\
\hline & Female & 324 & 35.5 \\
\hline \multirow[t]{4}{*}{ Age } & $<=25$ & 407 & 44.6 \\
\hline & $26-35$ & 372 & 40.7 \\
\hline & $36-45$ & 117 & 12.8 \\
\hline & $>=46$ & 17 & 1.9 \\
\hline \multirow[t]{4}{*}{ Education } & High school or below & 162 & 17.7 \\
\hline & Three year college & 213 & 23.3 \\
\hline & Bachelor & 392 & 42.9 \\
\hline & Master or above & 146 & 16.0 \\
\hline \multirow[t]{5}{*}{ Monthly income (RMB) } & $<=3000$ & 270 & 29.6 \\
\hline & $3001-5000$ & 366 & 40.1 \\
\hline & $5001-8000$ & 144 & 15.8 \\
\hline & $8001-10000$ & 52 & 5.7 \\
\hline & $>=10001$ & 81 & 8.9 \\
\hline \multirow[t]{3}{*}{ Frequency of social media use } & Several times per hour & 114 & 12.5 \\
\hline & Several times per day & 739 & 80.9 \\
\hline & Several times per week & 60 & 6.6 \\
\hline \multirow[t]{4}{*}{ Experience privacy invasion } & Never & 155 & 17.0 \\
\hline & Rarely & 589 & 64.5 \\
\hline & Often & 132 & 14.5 \\
\hline & Quite often & 37 & 4.1 \\
\hline
\end{tabular}


Table 3 Loadings and Cross-Loadings

\begin{tabular}{|c|c|c|c|c|c|c|c|c|c|}
\hline & MR & SE & SDI & FL & $\mathrm{AC}$ & $\mathrm{AR}$ & SDH & $\mathrm{PC}$ & SR \\
\hline SDI1 & .125 & .033 & .851 & .468 & .087 & .266 & .103 & -.180 & .170 \\
\hline SDI2 & .130 & .010 & .787 & .328 & .163 & .109 & .107 & -.233 & .174 \\
\hline SDI3 & .151 & .094 & .826 & .399 & .198 & .141 & .007 & -.212 & .162 \\
\hline SDH1(r) & .142 & .151 & .333 & .128 & .078 & .058 & .793 & -.021 & .304 \\
\hline SDH2(r) & .054 & .143 & .232 & .182 & .105 & .115 & .834 & .012 & .252 \\
\hline SDH3 & .085 & .121 & .291 & .166 & .189 & .067 & .807 & -.027 & .081 \\
\hline SDH4 & .064 & .037 & .273 & .156 & .114 & .112 & .838 & .019 & .122 \\
\hline SDH5 & .187 & .120 & .356 & .219 & .089 & -.077 & .712 & -.251 & .049 \\
\hline PC-AWA & .153 & .201 & -.184 & -.103 & .308 & -.027 & .007 & .842 & -.005 \\
\hline PC-COL & .187 & .139 & .015 & .082 & .174 & .111 & -.014 & .805 & -.048 \\
\hline PC-CON & .215 & .103 & .026 & .007 & .117 & .140 & -.352 & .848 & .144 \\
\hline SR1 & .379 & .290 & .043 & .101 & .108 & .135 & .348 & .086 & .752 \\
\hline SR2 & .421 & .240 & .244 & .084 & .006 & .175 & .331 & -.011 & .740 \\
\hline SR3 & .320 & .360 & .336 & .001 & -.016 & .178 & .036 & .010 & .857 \\
\hline MR1 & .783 & .147 & .094 & .138 & .127 & .150 & -.051 & -.019 & .489 \\
\hline MR2 & .813 & .190 & .094 & .097 & .059 & .238 & .183 & .087 & .292 \\
\hline MR3 & .771 & .211 & .102 & .110 & .086 & .134 & -.107 & .076 & .330 \\
\hline SE1 & .199 & .802 & .132 & .084 & .069 & .162 & -.033 & .089 & -.001 \\
\hline SE2 & .181 & .759 & .140 & .070 & .017 & .162 & .187 & .192 & .095 \\
\hline SE3 & .185 & .704 & .143 & .095 & .032 & .119 & -.029 & .013 & .133 \\
\hline SE4(r) & .086 & .839 & .104 & .252 & .238 & .080 & -.061 & .132 & .010 \\
\hline SE5 & .098 & .730 & .306 & .070 & .212 & .132 & .403 & .042 & .244 \\
\hline FL1 & .165 & .094 & .305 & .774 & .086 & .039 & .333 & -.050 & .129 \\
\hline FL2 & .079 & .116 & .263 & .729 & .199 & .068 & .416 & -.200 & .088 \\
\hline FL3 & .133 & .176 & .130 & .718 & .248 & .087 & .331 & -.070 & .169 \\
\hline AR1 & .190 & .189 & .082 & .069 & .089 & .801 & .147 & .065 & -.123 \\
\hline AR2 & .235 & .230 & .059 & .105 & .062 & .769 & .121 & .133 & .104 \\
\hline AR3 & .074 & .217 & .083 & .115 & .101 & .724 & .195 & -.055 & .146 \\
\hline AC1 & .244 & .042 & .103 & .246 & .867 & .267 & .099 & -.100 & .120 \\
\hline $\mathrm{AC} 2$ & .129 & .050 & .133 & .149 & .803 & .017 & .228 & .133 & .197 \\
\hline AC3 & .088 & .200 & .116 & .224 & .813 & .136 & .106 & .101 & .112 \\
\hline
\end{tabular}

Notes: 1 . SDI=self-disclosure intention; SDH=self-disclosure honesty; PC-AWA=privacy concern-awareness; $\mathrm{PC}-\mathrm{COL}=$ privacy concern-collection; $\mathrm{PC}-\mathrm{CON}=$ privacy concern-control; $\mathrm{SR}=$ social rewards; $\mathrm{MR}=$ monetary rewards; $\mathrm{SE}=$ =self-esteem; $\mathrm{FL}=$ flow; $\mathrm{AR}=$ application reputation; $\mathrm{AC}=$ application compatibility;

2. (r) reverse item. 
Table 4 Correlations and Descriptive Statistics

\begin{tabular}{|c|c|c|c|c|c|c|c|c|c|c|c|c|c|c|c|}
\hline & Mean & S.D. & C.R. & AVE & (1) & (2) & (3) & (4) & (5) & (6) & (7) & (8) & (9) & (10) & (11) \\
\hline 1.SDI & 4.04 & 1.26 & .862 & .675 & .822 & & & & & & & & & & \\
\hline 2.SDH & 3.17 & 0.88 & .897 & .637 & .478 & .798 & & & & & & & & & \\
\hline 3.PC-AWA & 5.12 & 1.04 & .864 & .680 & -.331 & -.322 & .825 & & & & & & & & \\
\hline 4.PC-COL & 4.23 & 1.12 & .813 & .592 & -.298 & -.347 & .430 & .769 & & & & & & & \\
\hline 5.PC-CON & 4.19 & 1.07 & .816 & .597 & -.303 & -.351 & .512 & .442 & .773 & & & & & & \\
\hline 6.SR & 4.52 & 1.26 & .827 & .616 & .286 & .370 & -.124 & -.102 & -.278 & .785 & & & & & \\
\hline 7.MR & 3.96 & 1.01 & .832 & .623 & .149 & .053 & -.313 & -.308 & -.335 & .413 & .789 & & & & \\
\hline 8.SE & 5.14 & 1.18 & .878 & .590 & .047 & .060 & .120 & .112 & .156 & .024 & .011 & .768 & & & \\
\hline 9.FL & 3.63 & 1.14 & .784 & .549 & .475 & .210 & -.243 & -.266 & -.202 & .170 & .123 & .088 & .741 & & \\
\hline 10.AR & 5.18 & 1.22 & .809 & .586 & .078 & .092 & -.107 & -.118 & -.104 & .053 & .214 & .112 & .162 & .766 & \\
\hline 11.AC & 4.58 & 1.10 & .867 & .686 & .094 & .170 & -.021 & -.088 & -.012 & .137 & .098 & .045 & .224 & .039 & .828 \\
\hline
\end{tabular}

Note: S.D., standard deviation; C.R., composite reliability; AVE, average variance extracted; Diagonal elements (bold) are the square roots of AVE. Off-diagonal elements are the correlations among constructs. For discriminant validity, the diagonal elements should be larger than the off-diagonal elements (Barclay et al. 1995).

Table 5 Path Coefficients of Control Variables

\begin{tabular}{llllllll}
\hline Dependent Variable & GEN & AGE & EDU & MI & PP & LE & PI \\
\hline Privacy Concern & $0.02 *$ & 0.02 & -0.01 & 0.03 & -0.11 & $-0.21^{*}$ & $0.19^{* * * *}$ \\
Social Rewards & 0.01 & 0.01 & 0.06 & 0.04 & 0.01 & 0.03 & -0.02 \\
Self-disclosure Intention & -0.09 & 0.05 & 0.02 & 0.04 & $0.17 *$ & $0.13^{* *}$ & $-0.24 * * *$ \\
Self-disclosure Honesty & 0.02 & 0.04 & 0.09 & 0.05 & 0.12 & 0.07 & $-0.08 * *$ \\
\hline
\end{tabular}

Notes. GEN=gender; AGE=age; EDU=education; INC=monthly income; $\mathrm{PP}=$ privacy policy; LE=law enforcement $\mathrm{PI}=$ privacy invasion.

${ }^{\dagger} p<0.1,{ }^{*} p<0.05, * * p<0.01,{ }^{*} * *_{p}<0.001$ (two-tailed test).

Table 6 Differences for the Path Coefficients

\begin{tabular}{llll}
\hline Dependent Variable & Pair of Coefficients & $\begin{array}{l}t \text { for Coefficient } \\
\text { Difference }\end{array}$ & $\begin{array}{l}p \text { for Coefficient } \\
\text { Difference }\end{array}$ \\
\hline Self-disclosure Intention & Social Rewards vs. Monetary Rewards & 3.41 & 0.001 \\
& Social Rewards vs. Privacy Concern & 18.7 & 0.000 \\
Self-disclosure Honesty & Social Rewards vs. Privacy Concern & 23.9 & 0.000 \\
\hline
\end{tabular}


Table 7 Results Summarize

\begin{tabular}{llll}
\hline Hypothesis & \multicolumn{1}{c}{ Path } & Relationship & Hypothesis Support \\
\hline H1 & Application Compatibility $\rightarrow$ Social Rewards & + & Supported \\
H2 & Application Reputation $\longrightarrow$ Social Rewards & + & Not Supported \\
H3 & Application Reputation $\longrightarrow$ Privacy Concern & - & Supported \\
H4 & Self-Esteem $\longrightarrow$ Privacy Concern & + & Supported \\
H5 & Flow Experience $\longrightarrow$ Social Rewards & + & Supported \\
H6 & Flow Experience $\longrightarrow$ Privacy Concern & - & Supported \\
H7 & Monetary Rewards $\longrightarrow$ Self-disclosure Intention & + & Supported \\
H8 & Monetary Rewards $\rightarrow$ Self-disclosure Honesty & + & Not Supported \\
H9 & Social Rewards $\longrightarrow$ Self-disclosure Intention & + & Supported \\
H10 & Social Rewards $\longrightarrow$ Self-disclosure Honesty & & Supported \\
H11 & Privacy Concern $\longrightarrow$ Self-disclosure Intention & & Supported
\end{tabular}

Table 8 Codes of Mobile Phone Operators (The First Three Digits of a Phone Number)

\begin{tabular}{ll}
\hline Operator & Operator Codes \\
\hline China Mobile & 4G: 134135136137138139150151152157158159 \\
& 3G: 187188 \\
China Unicom & 4G: 130131132155156 \\
& 3G: 185186 \\
China Telecom & 4G: 133153 \\
& 3G: 180189 \\
\hline
\end{tabular}

